\title{
Manufacturing systems in the 21st century
}

\author{
M. E. Merchant \\ Institute of Advanced Manufacturing Sciences, 1111 Edison \\ Drive, Cincinnati, Ohio, 45216 U.S.A. \\ Telephone: 513.948 .2067 \\ Fax: $\quad 513.948 .2007$ or 2109 \\ E-mail: merchant@iams.org
}

\begin{abstract}
Broad social-technical and specific long-term manufacturing trends are at work to shape manufacturing systems in the 21 st century. Of these the most powerful is the long-term industrial trend toward realistic and substantial accomplishment of highly human-resources-oriented computer integration, automation and optimised operation of the overall manufacturing enterprise. Today, that trend has two prongs, namely technological and managerial, each of which has now generated evolving methodologies which show high promise of beneficially shaping manufacturing systems in the 21 st century. The most promising of the evolving technological methodologies are concurrent engineering and artificial intelligence. The most promising of the managerial methodologies are those for a new approach to the structural organisation of manufacturing companies and those for the formation of "virtual companies". The impact of these trends and methodologies on the social fabric and the economy of the industrialised nations of the world in the 21 st century promises to be highly favourable, generating significant increase in the economic and social health and well being of those nations.
\end{abstract}

Keywords

Manufacturing, integration, CIM, human resources, concurrent engineering, artificial intelligence, virtual enterprise

The original version of this chapter was revised: The copyright line was incorrect. This has been corrected. The Erratum to this chapter is available at DOI: 10.1007/978-0-387-35357-9_22 


\section{INTRODUCTION}

What can we expect manufacturing systems to be like in the 21 st century? What will be their predominant technologies? What will be the nature of their human resource and social characteristics? What will be the impact of these on the social fabric and economy of the industrialised nations of the world?

How does one answer such questions? While no one can do so with certainty, let us explore what the possibilities seem to be in the light of what we already know. The approach that we will use in so doing is a two-part one. Since, as has been said by others, the past is a springboard to the future, we will first scrutinise what we know about the past in terms of what long-term trends have evolved therefrom which promise to shape the future of manufacturing systems. Here we will consider both broad socio-technological trends and specific trends in manufacturing. Secondly, we will examine the nature of the most promising of the methodologies which are now being deployed to enable manufacturing systems to respond most beneficially to those long-term trends. Finally we will consider where these methodologies are most likely to lead us in the light of their promise and of the long-term trends themselves.

\section{SOCIO-TECHNOLOGICAL TRENDS}

Two important socio-technological trends mark the recent decades of our modern world. In the intellectual field we see a marked and continuing trend in the direction of the waning of authoritarianism and the rise of tested thought. The backbone of this is, of course, the scientific method with its emphasis on joint use of experiment and analysis to provide tested principles. In the sociological field we see also the waning of authoritarianism and, here, the rise of individual freedom among humans. The two trends, therefore, have much in common and are, at times, almost indistinguishable one from the other.

These trends are bringing about a marked revolution in manufacturing. The intellectual change in the field is the most pronounced. Here we are witnessing the waning of the empirical approach to manufacturing processes and methods and the rise of the scientific-engineering approach to advancements in this area, i.e. the development of manufacturing engineering as a truly scientific and engineering activity. A less marked, but still distinct sociological-technological change is also occurring, as a result of the above trends, in that we are witnessing today a growing effort to free humans from the routine tasks of manufacturing, through the use of flexible automation. This is being done with an eye to making possible their employment in activities, which use and develop the unique creative abilities of mankind. As a corollary to this change, a waning of the demand for mass-produced items and a rise in the demand for more individuality in manufactured products is 
occurring, posing a requirement for economic manufacture of greater varieties of products in fewer numbers.

\section{TRENDS IN MANUFACTURING}

Over the years, a variety of trends and events have influenced manufacturing, which, taken together, have defined the long-term trend which we are experiencing today (and which we will describe at the close of this section). Basically, this process started with the invention of the "precision" machine tool in 1775, in the form of Wilkinson's boring machine. This event made possible the technological innovation of Watt's steam engine, which prior to that could not be built because of the absence of capability to bore a cylinder with out-of-roundness less than about $10 \mathrm{~mm}$. The combination of these two events spawned what has come to be known as the Industrial Revolution, marking the beginning of organised manufacturing in the form of manufacturing companies. As such enterprises grew in size and complexity, the problems of co-ordinating and managing the various activities which had to take place to design, plan the production and actually make the products became increasingly evident. As a result an organisational and social structure developed wherein independent departments were established, each having responsibility for performing and managing a given general type of these various activities. As size and complexity grew still further, particularly on the factory floor, innovative thinkers such as F.W. Taylor and Henry Ford carried this approach a step further in the form of division of labour. In this organisational and social structure, reduced to its basics, each worker became responsible for carrying out a single process or operation in the actual making of a product. However, in so doing, each was forced to work virtually independently of all the other workers who were carrying out the other processes or operations needed to make the product.

While these organisational approaches helped greatly to make order out of chaos, they nevertheless tended to reduce the operation of a manufacturing company to a welter of independent bits and pieces of activity, each performed by a given department or individual. As a result, interaction and communication between the various departments and individuals carrying out these activities suffered greatly. Therefore, the attainment of such attributes as overall efficiency and excellence of performance in the manufacture of products, although improved by the organisational approaches, was still handicapped by their shortcomings.

\subsection{The 1950s and 1960s}

Then, in the 1950s, came a technological event that held the potential, not at first recognised, to rectify that situation. This was the origination of the digital computer and its associated technologies and the initial hesitant application of such 
to manufacturing, as for example in the innovation of the numerical control of machine tools. As we pondered the implications of this event for manufacturing throughout the 1950s, it slowly became clear to us that these implications were enormous. The very fact that the digital computer is an extremely powerful systems tool made us recognise, first, that manufacturing is a system. Secondly, we then realised that the computer therefore offered staggering potential to operate manufacturing as a system, rather than operating it as a collection of virtually independent bits and pieces of activity as had been done in the past. Thus the concept of the Systems Approach to Manufacturing was born, in the early days of the 1960s (Merchant, 1961). As the capabilities of computer technology became increasingly clear, this concept had led us to the realisation of the fact that the digital computer had the potential to integrate the component activities of manufacturing (product design, production planning, production control, production processes, etc.) into a total system. Further, it became equally clear that such technology also held potential to flexibly automate those activities throughout the system and to optimise the operation, not just of those individual activities, but of the overall system as well. Thus the concept of the Computer-Integrated Manufacturing (CIM) System emerged also in the 1960s (Merchant, 1966) from the concept of the systems approach to manufacturing. That initial concept of the CIM system, put into graphical form in 1969, is illustrated in Figure 1.

\subsection{The 1970s and early $1980 \mathrm{~s}$}

During the 1970s and early 1980s the industrialised world engaged in a long frustrating struggle to develop and reduce to practice the concepts and technologies of the systems approach to manufacturing and the CIM system, to reap their inherent potential benefits. The nature and magnitude of those potential benefits began to be demonstrated as a few companies throughout the world began to achieve major improvements in performance, in the form of greatly:

- decreased costs

- increased productivity

- increased flexibility (agility)

- increased product producibility
- increased product quality

- decreased lead times

- increased worker satisfaction

- increased customer satisfaction

However, most companies, worldwide, were failing to attain nearly as great a magnitude of such benefits as was being experienced by these few companies. In fact, many of them actually experienced serious failures in the reduction of these new concepts and technologies to practice. The obvious question was-why? 


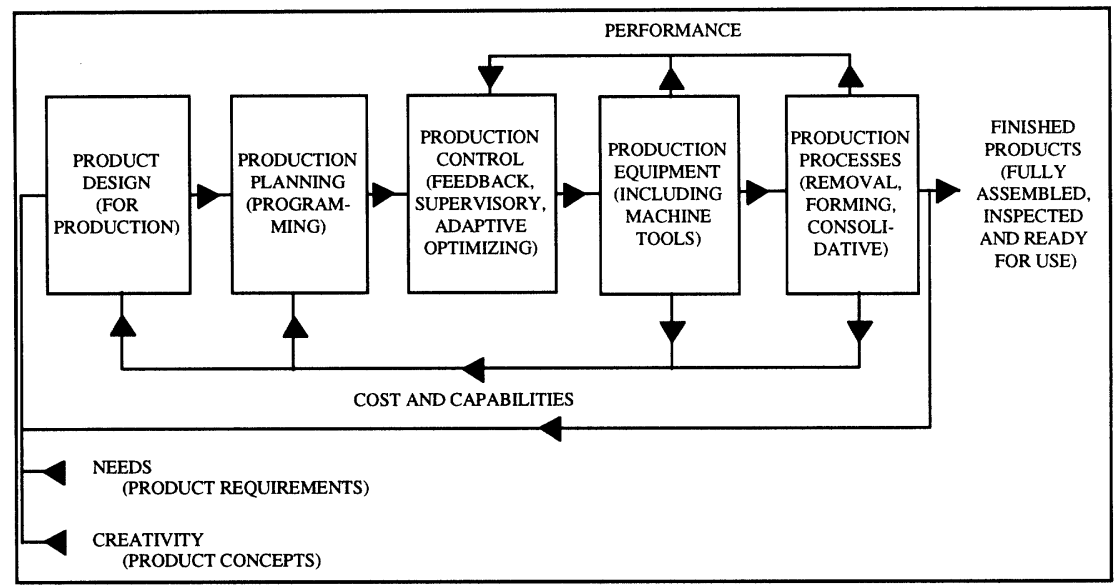

Figure 1: Initial Concept of the Computer-Integrated Manufacturing System, 1969.

\subsection{The late 1980s and the 1990s}

The answer to this question began to evolve during the late 1980s and into the 1990s, through benchmarking of the few companies experiencing the greatest degree of success. Slowly, understanding began to be grasped of the fact that failure to properly engineer the managerial human-resources factors of a manufacturing enterprise was defeating the technology! Further, it was found that CIM systems technology is especially sensitive to defeat by neglect of these factors. This new understanding is resulting, in the $1990 \mathrm{~s}$, in a new approach to the operation of the system of manufacturing. That approach can be summed up in the form of a new paradigm for manufacturing, namely:

Foster and utilise the capabilities of people to operate manufacturing and then develop and apply manufacturing technology in such a way as to support those human capabilities.

This of course means abandonment of the conventional practice of developing and applying manufacturing technology and then using the capabilities of people mainly to support that technology.

Evolving elements of this new paradigm currently comprise a variety of new practices, including:

- empower individuals with the full authority necessary to the carrying out of their responsibilities;

- use empowered multi-disciplinary self-directed teams to carry out the functions required to realise products; 
- empower use by these teams of such computer-supported systems integration techniques as concurrent engineering;

- empower a company's collective human resources to perform total quality management;

- so engineer both products and processes as to have minimum life-cycle impact on the human environment;

- make customers the focus of a company's operations;

- empower a company's suppliers to provide it with on-time supply of fully-qualified products;

- organise temporary teams of companies as virtual companies to realise products that are beyond the scope of any one of the companies.

The emergence of this understanding of the critical role which human resource factors plays in the success or failure of CIM-systems technology in the overall manufacturing enterprise has resulted in substantial rethinking of the initial CIM system concept. This has lead to the realisation that the initial CIM system concept needed to be broadened from one which encompassed primarily the technological operations of a company. It should be extended to one that encompasses both the technological and managerial operations of a company as an integrated manufacturing enterprise, with major emphasis on the human-resources-oriented managerial operations. The resulting broadened concept is well illustrated by the new CASA/SME Manufacturing Enterprise Wheel, shown in Figure 2, developed by the Computer and Automated Systems Association of the Society of Manufacturing Engineers (CASA/SME). As can be seen, this diagram well illustrates the integration of the technological operations of the system of manufacturing with the managerial operations of the overall enterprise, giving major emphasis to human-resources-oriented managerial operations and elements of the new paradigm for manufacturing described above.

\subsection{The new overall trend}

This new and evolving integrated socio-technological approach to the operation of the system of manufacturing has resulted, in the 1990s, in the emergence of a new and powerful long-term overall trend in world industry, as it approaches the 21st century, namely:

- A trend toward realistic and substantial accomplishment of highly human-resources-oriented computer integration, automation and optimised operation of the overall manufacturing enterprise.

In pursuing that overall trend, industry is increasingly recognising the dual nature of the concept of the CIM enterprise, encompassing both its technological and managerial operations. Therefore, its overall trend in this direction now has two prongs. The first of these is dedicated to development and implementation of new 


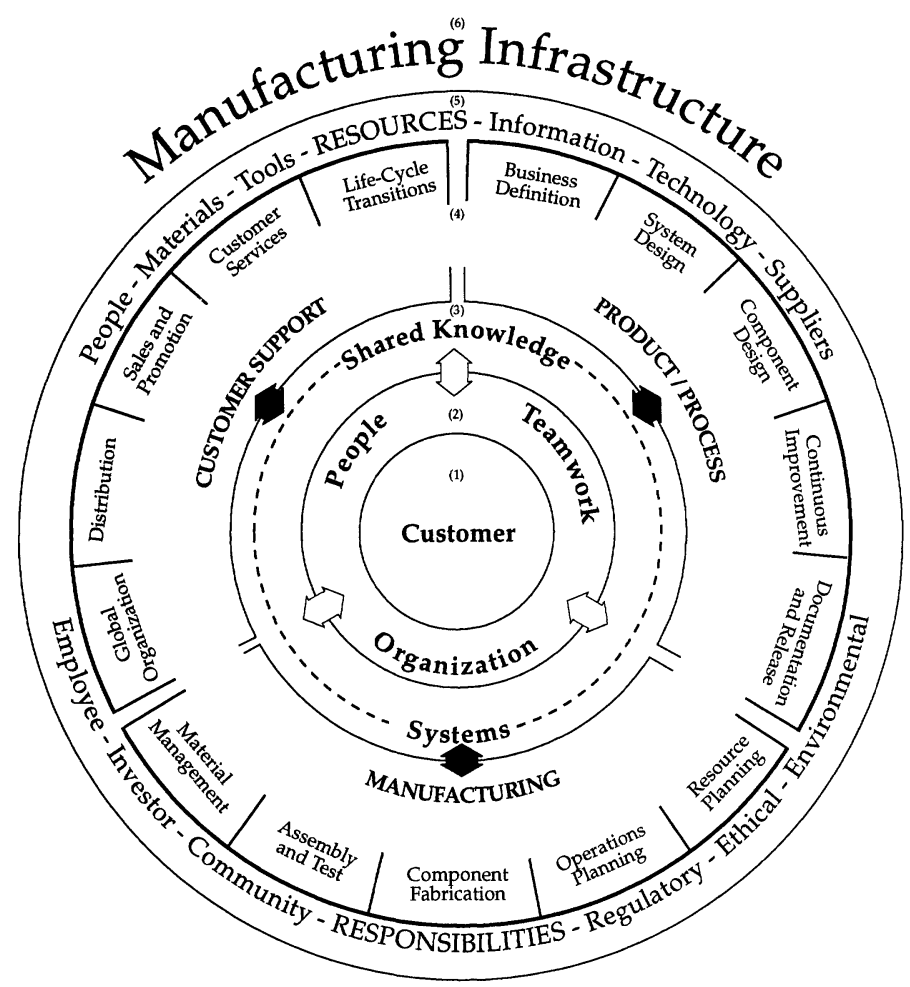

Figure 2: CASA/SME Manufacturing Enterprise Wheel Reprinted from the CASA/SME Manufacturing Enterprise Wheel, with permission from the Society of Manufacturing Engineers, Dearborn, Michigan, Copyright 1993, Third Edition

and integrated technological approaches to products and processes and the second to development and implementation of new highly human-resources-oriented managerial approaches to the operation of manufacturing enterprises. This overall two-pronged long-term trend in manufacturing, and its combination with the two long-term socio-technological trends described in section 2 of this paper, have now resulted in the generation of a variety of promising evolving methodologies intended to enable manufacturing to respond most beneficially to these trends. These methodologies fall into two main categories corresponding to the two prongs of the overall long-term manufacturing trend, namely technological and managerial. Let us therefore examine the nature and promise of these evolving methodologies for manufacturing in the 21 st century by means of four key examples. 


\section{TECHNOLOGICAL METHODOLOGIES}

Two main evolving technological methodologies, spawned in response to the long-term trends, appear to have greatest promise to beneficially shape manufacturing in the 21st century. The first of these is the evolving methodology of concurrent engineering - concurrent engineering of the conception and design of a product and of the planning and implementation of the system for its production and servicing. This methodology goes by many different names, such as simultaneous engineering, life-cycle engineering, design fusion, integrated and co-operative design, design for manufacture, etc. The second important evolving methodology is that of incorporation of artificial intelligence (AI) into the manufacturing system.

\subsection{Concurrent engineering}

In keeping with the new paradigm for manufacturing, concurrent engineering is accomplished by cross-disciplinary product realisation teams. However, the technology needed to support the human capabilities of the members of such teams is at present rudimentary, yet is critical to realisation of the full potential of CIM system technology enumerated earlier. Enabling technologies must be created to enhance the capabilities of humans with widely varying knowledge and responsibilities to share their understanding, intents and results and thus to operate manufacturing as an overall human system. Some very promising ideas concerning the nature of required enabling technologies were recently developed at the First CIRP International Workshop on Concurrent Engineering for Product Realisation (Kimura, 1992) held in Tokyo on June 27-28, 1992. This pondered the question of enabling technologies for concurrent engineering and concluded that at least four basic enabling technologies are needed, namely:

- A Decision Support System to evaluate facts and make proposals for action;

- A Virtual Teaming Support System for sharing of knowledge, understanding, and decision-making,

- A Concurrent Product Life Cycle Modelling System;

To model all phases of the life of the product, including not only its design and production, but also its market, customer, maintenance and repair

- A Time Responsive Intelligent Information System.

To support the above systems, providing intelligent storage and retrieval of information

The Workshop structured these four proposed systems into a proposed architecture for an overall system for performance of concurrent engineering, shown in Figure 3. As can be seen, this architecture comprises four modules, corresponding to the four systems above, plus humans at the centre. Appropriately, humans were made 
the centrepiece of this architecture because of the fact that they must be the overall driving force, as well as the controllers, of the functions to be performed in the conduct of concurrent engineering (i.e. the technology must support their capabilities).

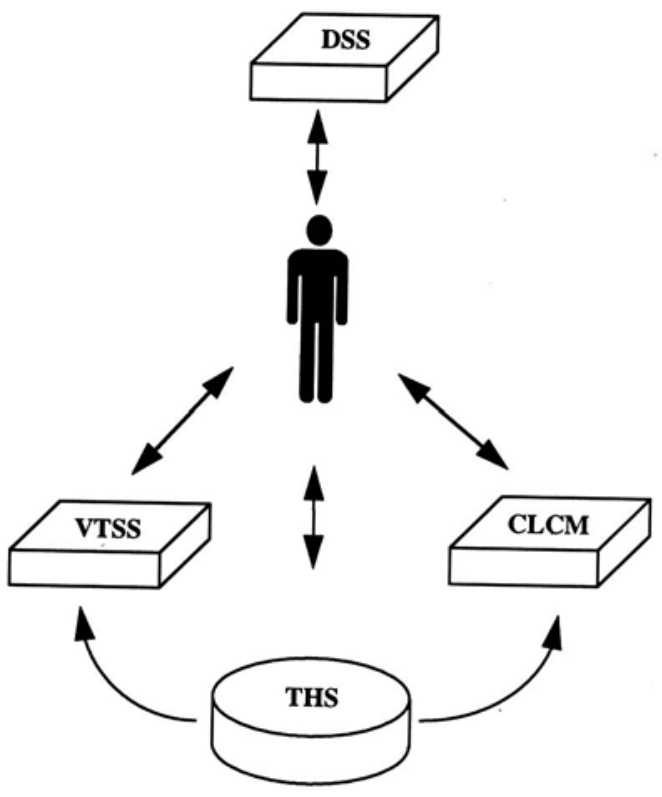

Figure 3: Architecture of System of Enabling Technologies for Performance of Concurrent Engineering.

Development of the technologies envisioned in this architecture will be a difficult and very sizeable task, which will take much time and large-scale effort to accomplish. However, the potential rewards are indeed great-probably even greater than we are able to realise at this early stage in the development.

\subsection{Artificial intelligence}

The second of the two main evolving technological methodologies having greatest promise to beneficially shape manufacturing in the 21 st century is that of artificial intelligence, as stated earlier. This is a methodology that probably has greater potential to revolutionise manufacturing in the 21 st century than any other known to us today. The reason for this lies in the fact that manufacturing is not, and never can be, a totally deterministic system. Effective operation of such a system therefore requires use not only of logic but also of inference and intuition. It is, 
after all, the admittedly limited human capabilities of inference and intuition which, nevertheless, make it possible for human beings to deal with the non-deterministic nature of the overall manufacturing system and to make that system operate, albeit woefully inefficiently, to produce useful products. Therefore, attainment of fully efficient operation will require the development of AI technology capable of extending the inference and intuition abilities of the human mind to far higher levels than have yet been realised.

The realisation of this tremendous potential of AI to revolutionise manufacturing in the 21 st century is surely the most challenging undertaking which the long-term trends described earlier in this paper have currently generated. It will require revolutionary developments in the technology of $\mathrm{AI}$ and massive R\&D efforts in manufacturing. However, the rewards will be magnificent!

\section{MANAGERIAL METHODOLOGIES}

Two main evolving methodologies appear to have greatest promise to beneficially shape manufacturing in the 21 st century. These, like the promising technological methodologies discussed above, have been generated by the three major long-term trends discussed in sections 2 and 3 above. The first of these is the evolving new methodology for structural organisation of manufacturing companies and the second is newly evolving methodology, still in its infancy, for the formation of virtual companies.

\subsection{New organisation structures}

The new approach to the structural organisation of manufacturing companies, which is now developing is a direct consequence of the interaction of two of the major long-term trends discussed earlier. These are the trends toward the waning of authoritarianism and the rise of individual freedom among humans and that toward realistic and substantial accomplishment, in industry, of highly human-resources-oriented computer-based automation, optimised operation and integration of the overall manufacturing enterprise. The first requires increasing recognition, in industry, of the innate individual capabilities of human beings, while the latter requires a human-resources-oriented systems approach to manufacturing. These, taken together, require a human-resources-oriented systems approach to the organisation of a manufacturing company. In the past, in the absence of computer technology and its tremendous capability to provide on-line communication of data and information throughout a company, we were all dependent on direct human-to-human verbal and written communication-with all its difficulties, inefficiencies and errors-to operate manufacturing. As a result, the organisation of conventional manufacturing tended to be made up of "walled-in" local "empires". With the arrival of computer-based capability for flexible 
automation of both the hard and soft components of manufacturing operations, this organisational structure led to the creation of "islands of automation" based on the local "empires". Further, almost no consideration was given to how these "islands" could be interfaced and integrated with each other. This situation created a real impediment to integration!

Methodology for surmounting this impediment is, however, now evolving. Companies that are most successful today in carrying out true manufacturing systems integration have found that the "local-empires" type of organisation is incompatible with accomplishment of such integration. Instead, they are finding that what is required is the establishment of a systems approach to organisation. Further, they are finding that the key ingredient of such an approach is the use of team-based management and team-based operations, founded on the establishment of co-operative relationships among all of the company's personnel. Thus the major organisational methodology being evolved today by those manufacturing companies striving to implement CIM effectively is that toward establishment of a systems approach to organisation utilising team-based management and team-based operations and founded on establishment of co-operative relationships. The operation of such a systems-oriented, people-centred organisation can then be well supported by CIM system technology.

\subsection{Virtual companies}

The evolving concept of virtual companies (Weimer, 1992) is quite new. Such companies are formed by organising a temporary "team" of companies to operate as though they were a single company in order to realise a product which is beyond the scope of any one of them. Thus, in a sense, this concept is an extension of the concept of team-based operation of a single company, with the teams being made up of companies rather than individuals. The concept is being developed internationally, with the United States and Japan being most active in that development. The Japanese version of it is sometimes described as a network of "holonic" plants, the term "holonic" being derived from the field of biology. There, holonic entities are defined as linked members of a biological system which have, at the same time, a life or their own.

Methodology and technology for the formation and operation of virtual companies is very much in its infancy. Its basic aim is to aid companies to become "plug compatible" with one another technologically and managerially (i.e. in their various distributed resources, both human and physical) so that they can perform their respective functions jointly. Thus, obviously, accomplishment of full computer integration, both within and between individual members of a virtual company, is an important facet of that methodology.

Although capability to form virtual companies is almost non-existent today, it cries out for creation of enabling technologies and human resource methodologies. This is because of its tremendous potential to provide a country's manufacturing 
industry with extremely high flexibility together with the synergy of pooled expertise. Obviously, development of methodology and technology to provide such capability presents a major challenge. It will require a major effort in manufacturing $\mathrm{R} \& \mathrm{D}$, preferably on an international scale, and a considerable period of time to accomplish such. However, again, the rewards will be magnificent!

\section{CONCLUSION}

In conclusion, let us consider the economic and social impact of pursuit of the long-term trends in manufacturing discussed here and the methodologies that these have spawned in the social fabric and economy of the industrialised nations of the world.

The basic wealth of a nation is created by the goods-producing sector of its economy, consisting of its manufacturing industry, its extractive industries (agriculture, fishing and mining) and its construction industry. In the case of industrialised nations, the manufacturing industry is the major creator of that basic wealth, generating approximately two-thirds of such. The other sector of a nation's economy, the service sector, does not create wealth directly and therefore depends on the goods-producing sector of the economy for its support. Thus increases in the standard of living, quality of life, employment and the general economic and social well being of a nation stem directly from decreases in the cost of creating its basic wealth. With manufacturing generating two-thirds of that wealth in industrialised countries, it follows that reduction of the cost of manufacturing (i.e. increase of manufacturing's cost effectiveness) is the major tool that such countries have to increase their economic and social health and well being.

We have seen in the preceding sections of this paper that the major long-term trends affecting manufacturing today are generating new and evolving technological and managerial manufacturing methodologies which have tremendous potential to dramatically increase the cost-effectiveness of manufacturing in the 21 st century. Thus, in the light of what is said in the preceding paragraph, pursuit of the development and implementation of those manufacturing methodologies holds great promise for highly significant increase in the economic and social health and well being of the world's industrialised countries. Since improvement in the economies of industrialised countries has been found to have a beneficial effect on the economies of other nations as well, it follows that world economic and social well being as a whole can benefit from the pursuit of such development and implementation. 


\section{REFERENCES}

Merchant, M.E., (1961), The Manufacturing Systems Concept in Production Engineering Research, Annals of the CIRP, Vol. 10/2, pp. 77-83.

Merchant, M.E, (1966), The Future of Manufacturing Technology, M.E. Merchant, Frontiers in Manufacturing Technology, Publications Distribution Service, University of Michigan, Ann Arbor, pp. 1-9.

Kimura, F., (1992), The first International Workshop on Concurrent Engineering for Product Realisation, Annals of the CIRP, Vol. 41/2, pp. 743-746.

Weimer, G., (1992), The New Emerging Form of Manufacturing, Controls \& Systems, Vol. 39, No. 4, pp. 68, 70.

\section{BIOGRAPHY}

Dr. Eugene Merchant received his degree of Bachelor of Science in Mechanical Engineering from the University of Vermont in 1936 and his Doctorate of Science degree from the University of Cincinnati in 1941. He carried out basic and applied research in manufacturing science and engineering at Cincinnati Milacron, Inc. for 46 years, serving finally as that company's Principal Scientist. Upon retirement from Milacron in 1983, Dr Merchant joined Metcut Research Associates, Inc. as Director of Advanced Manufacturing Research, moving more recently to the Institute of Advanced Manufacturing Sciences as Senior Consultant. He is a member of the National Academy of Engineering of the United States and has been a recipient of a variety of honours and honorary degrees in various countries. Dr Merchant's research has created important advances in the science of manufacturing, including the concepts of the systems approach to manufacturing and the computer integrated manufacturing system. 